\title{
LA UTILIDAD \\ DE LA FLORA AMERICANA \\ EN EL PROYECTO EXPEDICIONARIO \\ DE LA ESPAÑA ILUSTRADA
}

A. González Bueno

\section{RESUMEN}

El nuevo modelo político-econ6mico ideado por los ilustrados españoles propiciaría la ejecución de un ambicioso, utópico y, en cierto modo, original plan de reconocimiento y explotación de los recursos coloniales americanos con claros tintes monopolistas. El desarrollo de esta idea exigía el conocimiento y el inventario de los recursos naturales como etapa previa al proceso de comercialización. El desarrollo institucional de este proyecto es hoy bien conocido; finiquitado desde los comienzos del siglo XIX, la pesada máquina burocrática, ralentizada aún más con la entrada de las tropas francesas en España, permitirá que el desenlace final se retrase hasta 1831 .

\section{SUMMARY}

The new model, economical and political, devised by the enlightened Spanish was going to propiciate the execution of an ambitious, utopical and, in certain manner, original, plan of reconnaissance and exploitation of the colonial American facili- 


\title{
A. GONZÁLEZ BUENO
}

\begin{abstract}
ties with evident tints monopolists. The development of this idea demanded the knowledge and the inventory of the natural resources as previous stage to the process of commercialization. The institutional development of this project is today very well-known; Being over from the commencements of the XIXth Century, the heavy «bureaucratic» machine still more sluggish because of the entrance of the French troops to Spain, it will allow that the final outcome were delayed until 1831.
\end{abstract}

\section{En torno al concepto de Botánica en la España ilustrada}

La modernización del Estado, propiciada con el cambio dinástico de comienzos del XVIII, condujo a la postergación de viejos modelos en aras a la consecución de un nuevo orden político, social y científico; en el ámbito sanitario, las nuevas directrices propugnadas desde la Corte tratarán de fomentar el desarrollo de profesionales formados en ciencias positivas, en un intento de sustituir el anquilosado modelo escolástico ${ }^{1}$.

La Química y la Botánica se convierten en las disciplinas utilizadas para la renovación de la profesión farmacéutica; los conocimientos de estas disciplinas serán argüidos por los boticarios ilustrados como baluartes de su afán renovador frente a las actitudes defendidas por los boticarios conservadores ${ }^{2}$. La práctica de estas disciplinas por destacados profesionales farmacéuticos debe entenderse más como una actitud favorable a la reforma propiciada por los Borbones que como la capacidad teórica de abordar las disciplinas implicadas en el proceso renovador. Esta aceptación coyuntural de las nuevas ciencias dificultará su desarrollo al realizarse sin la necesaria reflexión teórica ${ }^{3}$, de modo que la evolución de estas disciplinas queda desligada del proceso de renova-

\footnotetext{
1 Lafuente, A.; Puerto, F. J. y Calleja, M. C. (1988): "Los profesionales de la sanidad tras su identidad en la ilustración española.» En: SÁnChez Ron, J.M. (ed.), Ciencia y Sociedad en España: de la Ilustración a la Guerra Civil, pp. 71-92. Madrid.

2 Un análisis de detalle en González Bueno, A. y Puerto Sarmiento, F. J. (1988): «Ciencia y Farmacia durante la Ilustración.» En: Sellés, M.; Peset, J. L. y Lafuente, A. (comp.). Carlos III y la ciencia de la Ilustración, pp. 127-140. Madrid.

3 Un ejemplo de este aserto en González Bueno, A. y Francés CaUSAPÉ, M. C. (1991) «Divulgación científica en la Farmacia española ilustrada: El Examen Pharmaceutico... de Francisco Brihuega». Llull, 14, pp. 495-505. Zaragoza.
} 


\section{LA UTILIDAD DE LA FLORA AMERICANA EN EL PROYECTO EXPEDICIONARIO}

ción institucional y sólo cuando la reforma quede superada se producirán aportaciones científicas de interés intrínseco.

Así entendida, la actitud de los ilustrados españoles hacia la Botánica debe considerarse, en sus inicios, más como una actitud política que científica; el apoyo que la Corona española ofrece a la disciplina se realiza siguiendo las directrices que habrán de ser comunes a la reforma ilustrada: centralización, militarización, creación de instituciones de nuevo cuño, nuevos procesos de profesionalización e institucionalización, etc. Esto es, el desarrollo institucional de la Botánica en la España ilustrada aparece ligado a una coyuntura política concreta, no es el resultado del acrecentamiento de una escuela preexistente. Como en tantas otras situaciones creadas en el período ilustrado, la introducción de las nuevas teorías botánicas en España se produce sin la necesaria crítica intracientífica; importa el uso de la ciencia más que ésta en sí misma; las preocupaciones de índole filosófica y metodológica están bien alejadas de esta recepción de saberes nuevos ${ }^{4}$.

La Botánica, la ciencia utilizada como instrumento de la reforma sanitaria ilustrada, se incorpora, como herramienta política, al ambicioso proyecto de inventario y comercialización de las riquezas coloniales coordinado por C. Gómez Ortega; para él, y para sus discípulos, la Botánica tiene una clara concepción pragmática, es, ante todo, una ciencia de la cual se pueden y deben obtener beneficios económicos y sanitarios; en sus propias palabras:

\footnotetext{
«De aquí se infiere la utilidad e importancia del estudio de la Naturaleza, en cuyos tres Reinos no existe producción alguna que no pague o esté pronta a pagar tributo al hombre siempre que éste se dedique a aclarar sus derechos por medio de su aplicación y diligencia (...) Pero así como el reyno Vegetal excede notablemente en el número de objetos a los otros dos, lleva a ambos muchas ventajas en la multiplicidad y calidad de los beneficios que presta a la especie humana. La Botánica, que es la Ciencia que enseña a conocer y distinguir los vegetales, abraza también la noticia de sus usos.» ${ }^{5}$.
}

\footnotetext{
${ }^{4}$ Sobre este aspecto cf. González Bueno, A. (1990): «Penetración y difusión de las teorías botánicas en la España ilustrada». En: FERnÁNDEZ PÉREZ, J. y GonZález TASCÓn, J. (eds.) Ciencia, Técnica y Estado en la España ilustrada, pp. 381-395. Zaragoza.

5 Gómez Ortega, C. y Palau, A. (1788): Curso elemental de Botánica... Madrid.
} 


\section{A. GONZÁLEZ BUENO}

C. Gómez Ortega asume los planteamientos utilitarios enunciados por J. Quer, M. Barnades y otros botánicos ilustrados, a quienes interesa el inventariado y, sobre todo, la explotación de los recursos naturales, plasmándolos en un proyecto desde donde los profesionales de la ciencia de las plantas lograrán mostrarse útiles en sí mismos y en su disciplina frente a las necesidades de renovación de la España borbónica ${ }^{6}$.

Su postura entrará en claro enfrentamiento con la mantenida por A. J. Cavanilles, su sucesor al frente del Real Jardín madrileño; los estudiosos de la figura del clérigo valenciano han centrado la polémica mantenida frente a C. Gómez Ortega y su escuela en la adscripción estricta de éstos a los principios linneanos para la determinación de los caracteres genéricos frente a la postura, más ecléctica, defendida por A. J. Cavanilles ${ }^{7}$; tras esta discrepancia teórica se esconde otra más profunda, relativa al concepto mismo de la disciplina:

«La Botánica tiene límites como las demás ciencias y artes; que si presta auxilios a la medicina, economía y artes, no debe entrar en el santuario de ellas, ni atribuirse lo que á estas pertenece.. ${ }^{8}$.

Las palabras del valenciano contrastan con las escritas por $\mathrm{H}$. Ruiz en apoyo de la visión utilitarista defendida por los partícipes en el proyecto expedicionario:

\footnotetext{
${ }^{6}$ Una visión general, con justificación detallada y precisa, en PUERTo SARMiento, $\mathbf{F}$ J. (1987): La ilusión quebrada: Botánica, sanidad y política científica en la España ilustrada. Barcelona. Una muestra de los planteamientos de estos botánicos ilustrados en QuER, J. (1762-1784): Flora española... Madrid (en particular la dedicatoria del tomo I, $12 \mathrm{pp.}$ [sin paginar]) y Barnades, M. (1767): Principios de Botánica... Madrid (en especial el apartado II del «Discurso preliminar...» titulado «Necesidad y recomendación de la Botánica» [pp. 24-41]).

7 ÁLVAREZ LÓPEZ, E. (1945): «Cavanilles. Ensayo biográfico-crítico.» Anales del Jardín Botánico de Madrid, 6(1), pp. 1-64. Ib. (1946): «Lamarck, Cavanilles y Condillac». Boletín de la Real Sociedad Española de Historia Natural (tomo extraordinario), pp. 77-87. Madrid. Ib. (1953): "Algunos aspectos de la obra de Ruiz y Pavón.» Anales del Instituto Botánico A. J. Cavanilles, 12(1): 5-111. Madrid.

${ }^{8}$ Cavanilles, A. J. (1796): Colección de papeles sobre controversias botánicas. Madrid; el texto transcrito en pág. 14.
} 


\title{
LA UTILIDAD DE LA FLORA AMERICANA EN EL PROYECTO EXPEDICIONARIO
}

\begin{abstract}
«... y esto sin hacer la crítica de lo que falta á la Historia de cada planta en que siempre se ciñe nuestro Impugnador [A.J. Cavanilles] al discernimiento del género y de la Especie sin dar la menor noticia de los usos y virtudes, como si este conocimiento no fuera el resorte del Botánico, á quien de poco serviría la estéril habilidad de distinguir todas las Plantas del Universo, ignorando sus propiedades y usos que pueda hacerse con ellas.n'.
\end{abstract}

Para los botánicos integrantes de este proyecto de reconocimiento y explotación del mundo vegetal americano la anotación de las virtudes y usos de las plantas es algo más que el sólo complemento a la descripción, es la razón motivadora del esfuerzo realizado; los expedicionarios americanos no son taxónomos en sentido estricto, aunque tal sea su aportación hoy más valorada; su Botánica es farmacéutica y se separa conceptualmente de la practicada por A. J. Cavanilles y su escuela ${ }^{10}$; para los primeros lo esencial es el vires et usus, para los segundos el nomen. Una polémica que trasciende la delimitación conceptual de la propia disciplina y que habrá de afectar seriamente al desenlace del proyecto de expediciones botánicas coordinado por C. Gómez Ortega.

\section{El proyecto ilustrado de las expediciones botánicas: génesis y desarrollo}

Mas abandonemos el concepto de Botánica para adentrarnos en la génesis y desarrollo del propio proyecto de las expediciones botánicas; en él confluyen intereses de variada índole: relaciones internacionales, reforma sanitaria colonial, introducción de nuevas ciencias, remodelación del mercado colonial, afianzamiento cultural de la presencia metropolitana, etc.; todos le definen y colaboran a darle forma ${ }^{11}$. Un proyecto

${ }^{9}$ Ruiz, H. (1796): Respuesta para desengaño del público á la impugnación que ha divulgado... Joséph Antonio Cavanilles... Madrid; reproducida en Cavanilles, A. J.: Op. cit. nota 8, pp. 109-274; el texto transcrito en p. 260.

10 GonZález Bueno, A. (1988): «Los estudios criptogámicos en España (1800-1820): una aproximación a la Escuela Botánica de A. J. Cavanilles». Llull, 12, pp. 51-74. Zaragoza.

11 Un análisis de este proyecto en Puerto Sarmiento, F. J. y González Bueno, A. (1993): «Política científica y expediciones botánicas en el programa colonial español ilustrado.» En: Lafuente, A.; Elena, A. y Ortega, M. L. (eds.): Mundialización de la ciencia y cultura Nacional: 331-339. Madrid. 


\section{A. GONZÁLEZ BUENO}

remodelado progresivamente en el tiempo, a medida que se integran en él nuevos objetivos distorsionantes de sus metas pristinas, pero subyacente a todos permanece el deseo expreso de aclimatar plantas americanas en el territorio metropolitano:

«Si en cada Paquebot del Correo marítimo de Canarias, Habana, Cartagena, y Buenos-Ayres se traxera un caxon (...) con algunas plantas de las más apreciables de aquellas regiones, nos haríamos dueños en pocos años de la mayor parte de las riquezas vegetables de la América Española, que tienen sobre las minerales la ventaja de poderse propagar y multiplicar al infinito una vez poseídas y connaturalizadas. ${ }^{12}$

El texto, procedente de la Instrucción... publicada por C. Gómez Ortega en 1779, es buena prueba del interés despertado en la Corte hacia esta nueva vía de obtener riquezas; muy distinta es esta Instrucción... de la publicada años antes, en 1776, por P. Franco Dávila: mientras en la del director del Real Gabinete se solicitan «las propiedades curiosas de la Naturaleza" ${ }^{13}$ en ésta el pragmatismo es explícito, y los deseos de romper la primacía comercial de otros Estados europeos está patente.

Un análisis de los materiales solicitados en la Instrucción... pone de manifiesto que, en lo que a lo medicinal respecta, lo requerido con más énfasis son las plantas febrífugas (muy en especial las quinas) y antivenéreas; las virtudes más comunes atribuidas a las plantas americanas desde los conocimientos disponibles por los gestores del proyecto. Lo no medicinal, y esto es lo más original de la aventura expedicionaria española, tiene menos representación en las solicitudes formuladas; a las plantas con virtudes terapéuticas siguen, muy de lejos, las de valor alimenticio, sin hacerse de las comestibles apenas mención. En definitiva,

12 GÓmEz ORTEGA, C. (1779): Instrucción sobre el modo más seguro y económico de transportar plantas vivas... Madrid; la cita en p. 22. Hay edición facsimilar, con estudio introductorio de F. J. Puerto, impresa en Burgos (1992).

${ }^{13}$ La Instrucción... reproducida en Romero Castillo, A. (1966): Don Pedro Franco Dávila (1711-1786). Guayaquil; cf. pp. 20-42. En lo relativo a sus intereses es ilustrativa la lectura de FrANCo DÁvILA, P. (1767): Catalogue systematique et raisonné des curiosités de la nature et de l'art, qui composent le Cabinet de M. Davila... Paris. 


\section{LA UTILIDAD DE LA FLORA AMERICANA EN EL PROYECTO EXPEDICIONARIO}

la Instrucción... de 1779 nos revela el carácter medicinal con que la empresa es acometida por la metrópoli ${ }^{14}$.

Ante la propuesta del fisiócrata A. R. Turgot, encuadrable dentro de la política de aclimatación diseñada por el gobierno galo, de enviar una expedición dedicada a estudiar el mítico territorio del Perú, la Corte española responderá con la creación de una Expedición propia, a la que podría incorporarse el enviado francés ${ }^{15}$; la premura con que fue diseñada esta misión queda explicitada en la propia Instrucción a que deberán arreglarse los sugetos destinados por S. M. para pasar a la América meridional ${ }^{16}$, construida a fines de 1776 , y en la que la visión utilitarista de C. Gómez Ortega frente a la Naturaleza americana está ya presente; de la lectura de esta Instrucción se desprende una cierta incapacidad de los organizadores españoles para hacerse cargo de la empresa, no hay normas precisas y J. Dombey, el botánico francés, es reconocido en ellas como la única autoridad competente en temas científicos ${ }^{17}$, pero sí están claros los fines del viaje:

"Siendo el objetivo principal de este viage, no tanto la pura nothicia theorica de nuevos vegetales útiles como su adquisición para que se introduxca, y propague su uso en España, y aun en los demás paises con aumento de las ciencias, del Comercio, y en beneficio de la Humanidad, no deberán contentarse nuestros Botánicos con examinar las plantas, describirlas, y conservar sus esqueletos en los Herbarios. Cuidarán también diligentemente de hacer remesas de cebollas, Céspedes,

${ }^{14}$ Un análisis de detalle, con una cuantificación de datos que sustenta lo aquí enunciado, en GonzÁlez BuEno, A. (1992): «Virtudes y usos de la Flora Americana: una aproximación al carácter utilitario de las Expediciones Botánicas en la España ilustrada.» En: Lafuente, A. y Sala Catalá, J. (eds.). Ciencia colonial en América, pp. 78-90. Madrid.

15 Cf. Clement, P. (1988): «La participación francesa en la Expedición Botánica al Perú (1777-1788)». En González BuENo, A. (ed.): La Expedición Botánica al Virreinato del Perú (1777-1788), vol. 1, pp. 19-40. Barcelona, 1988.

16 Reproducidas en BARREIRo, A. J. (1931) (ed.): Relación del viaje hecho a los Reynos del Perú y Chile por los botánicos y dibuxantes... su autor Don Hipólito Ruiz. Madrid; la Instrucción... en pp. 365-374.

17 "Tendrán cuidado de preguntarle, y de recurrir a él en los casos en que crean tener necesidad, o serles útil el valerse de sus luces, y experiencias; sin que por esto sean, ni puedan creerse dependientes de él, ni que él pueda tratarlos cono a tales en ningún caso, ni materia.» Art. 2. ${ }^{\circ}$ de la Instrucción... (Barreiro, A. J., Op. cit. nota 16, p. 365). 


\section{A. GONZÁLEZ BUENO}

mugrones, y plantas vivas siempre que haya oportunidad (...) y en el mismo Jardín se cuidarán de multiplicarlas, y de hacer las experiencias convenientes para familiarizarlas, con el clima, y suelo de algún territorio de España...» ${ }^{18}$.

Del análisis simultáneo de envíos de semillas a la Corte, siembras en el Real Jardín y acciones asignadas a los vegetales herborizados, puede discernirse un primer período, entre 1782 y 1794 , donde la originalidad medicinal propugnada por C. Gómez Ortega queda preterida a favor del fisiocratismo francés; la influencia de J. Dombey se hace manifiesta en los primeros logros del proyecto: en el Real Jardín de Madrid se aclimatan, con preferencia, especies comestibles americanas; las chirimoyas, zapotes, fríjoles y nueces condimentarias se sembrarán con profusión durante estos años y prosperarán durante los siguientes.

En 1794 ocurren cambios importantes en el acontecer histórico del proyecto americano; es el último en que el nombre de C. Gómez Ortega se recoge en los «diarios» de la Oficina de la Flora Americana y los «libros de siembra" del Real Jardín comienzan a abandonar la nomenclatura propuesta por los expedicionarios americanos para recoger la de A.J. Cavanilles. No parecen meras coincidencias; estas situaciones deben ser directamente correlacionadas con la exoneración sufrida por Floridablanca, su reclusión en Pamplona y la posterior llegada al Gobierno, en 1792, del Conde de Aranda.

La segregación de C. Gómez Ortega del proyecto americano no supone el abandono de la búsqueda de virtudes medicinales en la flora del Nuevo Mundo; en el Real Jardín madrileño, la siembra de medicinales americanas cobrará su mayor auge entre 1794 y 1802, sobre todo purgantes (casia, simpatich) y la ratanhia, una de las innovaciones terapéuticas incorporadas por H. Ruiz a la farmacología europea, sobre la que habremos de volver luego; los expedicionarios en México, también incluidos en este mismo programa, estudiarán, entre 1799 y 1802, la aplicación terapéutica de vegetales indígenas en el Hospital General de Naturales.

En definitiva, creemos poder entrever, entre 1795 y 1802, una maduración del primer proyecto americano, donde sin perder el interés medicinal del mismo, antes bien acentuando esta línea investigadora, se pro-

18 Art. $14 .^{\circ}$ de la Instrucción... (cf. Barreiro, A., Op. cit. nota 16, pág. 371). 
fundiza en el valor medicinal de los materiales americanos, pero ya no bajo directrices de búsqueda concretas. Asistimos al redescubrimiento de la Naturaleza medicinal indígena, queda superada una etapa de batida del territorio americano a la búsqueda de febrífugos y antivenéreos, con los que paliar los problemas de salud europeos, tal y como se propugna en las diferentes instrucciones dirigidas a los expedicionarios desde la Corte.

El año de 1802 es otra de las fechas cruciales en el proyecto expedicionario; el nombramiento de A. J. Cavanilles como director único de las expediciones botánicas, al poco de obtener la dirección del Real Jardín, traspasa a manos del clérigo valenciano unos poderes nunca ostentados por el propio C. G. Ortega. Los expedicionarios peruanos se retiran del Real Jardín madrileño, no vuelven a utilizar sus semilleros; los destinados en México, que inician este año su vuelta a la Península, depositarán sus semillas en el Real Jardín pero no participarán en sus siembras. Es el año de la agonía de este proyecto americano, que lanza sus últimos estertores con la aparición del tercer volumen de la Flora Peruviana..., el último salido de las prensas de G. Sancha; no hay fondos para proseguir la empre$\mathrm{sa}^{19}$.

Los equipos americanos, los creados a la sombra de las expediciones a los Virreinatos de Perú y Nueva España, mantienen sus relaciones con la metrópoli hasta la declaración de independencia formulada por los nuevos gobiernos en sus respectivos territorios ${ }^{20}$, pero el grueso de su actividad seguirá vinculada con la de los expedicionarios en España a través de la Oficina Botánica. Una labor marginal por cuanto se realiza con tal carencia de medios económicos que impide la dedicación de los expedicionarios al proyecto.

\footnotetext{
19 La publicación de la Flora Peruviana... y los trabajos realizados en la Oficina Botánica han sido estudiados por Rodríguez NozAL, R. (1993): La "Casa de la Flora Americana" (1788-1835) y la marginación del proyecto de las Expediciones botánicas ilustradas. Madrid. Véase también su colaboración en este volumen.

${ }^{20}$ Resulta de interés comprobar la procedencia geográfica de las siembras de semillas americanas efectuadas en el Real Jardín (cf. GonZÁlez BuENo, A. y MuÑoz GarMENDía, F. (1993): «Las semillas de la América hispana en el Real Jardín Botánico de Madrid: una aproximación a través de los Libros de Siembra (1777-1822).» En: Madrid en el contexto de lo hispano desde la época de los descubrimientos, pp. 1369-1382. Madrid.
} 


\section{A. GONZÁLEZ BUENO}

\section{Una valoración de los resultados}

Así las cosas ¿cabe hablar de un proyecto fracasado? Desde luego no en su totalidad si se prescinde del carácter nacionalista de la empresa. El programa colaboró a la reforma de la estructura colonial, introdujo el estudio de la Botánica en nuestros territorios americanos y logró la preparación de buenos continuadores de la actividad científica bosquejada por los expedicionarios; se formaron botánicos, pero botánicos americanos, baluartes del movimiento libertador, algo bien distinto de lo deseado por las mentes centralistas del equipo gestor metropolitano ${ }^{21}$.

En lo concerniente al ámbito científico nos encontramos con una situación similar; no nos fue posible publicar una "Flora Americana» con la magnificencia deseada por la Corona española; no pudimos mostrar al resto de Europa las bellezas y utilidades de la Naturaleza de nuestro Imperio; no hubo ocasión de pregonar la grandiosidad de las posesiones españolas; pero sí estuvieron disponibles los materiales para que otros científicos se ocuparan de describir la flora americana, y los índices de semillas del Real Jardín, los posteriores a 1804, recogen las denominaciones que G. Bentham, C. S. Kunth, E. G. von Steudel y, sobre todo, las que A.P. De Candolle divulgara en su Prodromus Systematicis Naturalis Regni Vegetabilis... (París, 1823-1873). Los manuscritos de los expedicionarios españoles quedaron inéditos, pero su labor no fue baldía, permitió que otros científicos europeos dieran a conocer la exhuberancia de la flora americana. Claro que ésta tampoco era la forma que los ilustrados españoles idearon para divulgar sus resultados; piénsese en

\footnotetext{
21 Sobre las relaciones entre los movimientos científicos y libertadores americanos cf. Peset, J. L. (1987): Ciencia y libertad. Madrid; también PESET, J. L. (1993): «Ciencia e independencia en la América española.» En: LAfuente, A.; Elena, A. y OrTEga, M. L. (eds.): Mundialización de la ciencia y cultura nacional, pp. 195-217. Madrid. Para la introducción del estudio de la Botánica en los territorios americanos cf. AcEVEs PASTRANA, P. (1987): "La difusión de la Ciencia en la Nueva España en el siglo XVIII: la polémica en torno a la nomenclatura de Linneo y Lavoisier.» Quipu, 4(3), pp. 357-385. México. Estrella, E. (1993): "Introducción del sistema linneano en el Virreinato del Perú.» En: Lafuente, A.; Elena, A. y Ortega, M. L. (eds.): Mundialización de la ciencia y cultura nacional, pp. 341-348. Madrid. PUIG-SAMPER, M. A. (1993): «Difusión e institucionalización del sistema linneano en España y América.» En: LAFUente, A.; ElENA, A. y ORTEGA, M. L. (eds.): Mundialización de la ciencia y cultura nacional, pp. 349-359. Madrid.
} 
la polémica suscitada en torno a la publicación de la obra de Ch. L'Heritier con materiales de J. Dombey ${ }^{22}$.

Con todo, en una tercera vía sí podemos hablar, aunque también con ciertas reticencias, de éxito en este programa expedicionario: en la incorporación de nuevos remedios terapéuticos a la Farmacopea española; los estudios de los expedicionarios tienen su impacto en la edición de 1817; sólo se introducirá una planta, Kraemeria triandra Ruiz \& Pav., la ratanhia, pero, y esto es lo más significativo, en algunas quinas (Cinchona lanceolata Ruiz \& Pav., Cinchona nitida. Ruiz \& Pav.) se sigue la descripción botánica de los viajeros, y en algunos bálsamos se hace expresa mención de los estudios de éstos, asignándoles la autoría «Flor. Peruv.»; es en esta edición de 1817 donde los Códigos españoles logran la primera aproximación al arsenal terapéutico americano, eliminando este calificativo geográfico de las plantas sólo índicas y puntualizando, con mayor precisión, la utilidad terapéutica de las drogas del Nuevo Mundo. Tras la incorporación de los trabajos de los expedicionarios españoles al Perú (1777-1788), pues otros apenas fueron considerados ${ }^{23}$, se logra disponer de una mejor caracterización de la materia médica americana, limando y corrigiendo el arsenal conocido, mas la aportación de novedades es parca, como vemos. Quedaron fuera el yalhoy, el bejuco de la estrella, el caucho, la violeta estrellada, la polígala mejicana y otros muchos remedios de acción comprobada; éstos irán siendo incorporados a nuestras Farmacopeas a lo largo del siglo XIX; entonces tomaremos como referencia otros Códigos europeos, fundamentalmente franceses, olvidándonos que las mismas observaciones yacían inéditas en los archivos de la misma Real Academia de Medicina que editaba nuestras Farmacopeas;

\footnotetext{
22 Un comentario a la utilización de los materiales procedentes de las expediciones ilustradas por los botánicos europeos decimonónicos en el estudio introductorio de GoNzález Bueno, A. y Navarro Aranda, C. (1989) para la edición de Ruiz, H. y Pavón, J.: Laurographia Florae Peruvianae et Chilensis..., pp. [7-15]. [Bilbao]. El incidente diplomático creado en torno a la publicación del Stirpes Novae... de Ch. L'Heritier analizado someramente en Puerto Sarmiento, F. J., González Bueno, A. y Gómez Alonso, E. (1989): «Viret et usus: notas sobre etnobotánica peruana en los diarios de Hipólito RuIz (1777-1788)». En: Le piante medicinali e il loro impiego in Farmacia nel corso dei secoli, pp. 171-175. Piacenza.

${ }^{23}$ Sólo la inclusión, en la edición de 1803, de la raíz de ágave, probablemente siguiendo las indicaciones de los expedicionarios en el Virreinato de Nueva España (1787-1803). El remedio no trascendió a otras farmacopeas europeas.
} 


\section{A. GONZÁLEZ BUENO}

algunos serán desempolvados, con cien años de retraso, y sus datos incorporados entonces a nuestros textos oficiales ${ }^{24}$.

España no supo encontrar en América la panacea soñada por los políticos ilustrados, pero América dispuso, gracias al programa expedicionario que venimos tratando, de centros de formación botánica y los estudiosos europeos tuvieron acceso a los materiales con los que describir la rica y desconocida flora americana y de estudiar sus propiedades terapéuticas. El proyecto ilustrado de las expediciones botánicas americanas, entendido como instrumento de colonialismo, debe ser considerado un fracaso, pero los objetivos científicos, quizás nunca perseguidos, se cubrieron, si bien indirectamente, con cierto esplendor.

24 Sobre la incorporación de remedios americanos a las Farmacopeas españolas cf. González Bueno, A., Rodríguez Nozal, R. y Sánchez Sánchez, P. (1991): "Una visión del arsenal terapéutico vegetal americano desde las Farmacopeas españolas (1739-1954).» Anales de la Real Academia de Farmacia, 57(2), pp. 351-364. Madrid. Con más detalle, en lo que al fenómeno expedicionario respecta, Rodríguez NozaL, R.; FrancÉs Causapé, $M$. C., GonZález Bueno, A. y SÁnchez SánCheZ, P. (1991): «La influencia de las expediciones botánicas ilustradas en las farmacopeas españolas.» En: DíEz TORRE, A. R. y als. (coord.) La Ciencia española en Ultramar, pp. 235-247. Madrid. 